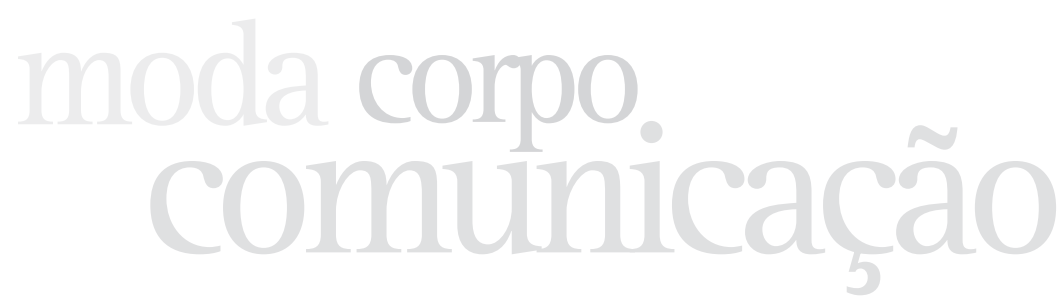

A consolidação de qualquer área do saber requer necessariamente a organização de um pensamento pautado em direcionamentos que retomem e ampliem, que diversifiquem e correlacionem os aspectos teóricos que embasam seus estudos, bem como demonstrem a aplicabilidade metodológica utilizada, cujo resultado é o entendimento dos processos de produção de sentido.

0 trabalho que ora ganha estampa trilha justamente esse percurso, ao retomar os estudos da semiótica e os da sociossemiótica, com o intento de, ao mesmo tempo, analisar o corpus constituinte da pesquisa e dar sua contribuição para o arcabouço teórico e metodológico sob os quais repousam seus argumentos, culminando com a contribuição de Adriana Baggio para uma Semiótica da Moda na perspectiva da grande área da Comunicação.

0 artigo apresenta a montagem de um mosaico de sentidos provenientes dos discursos relacionados à manifestação social da categoria "feminino", centrando suas análises nas publicidades de revistas de grande representatividade no espaço brasileiro e discutindo os simulacros em torno desse gênero na sua construção figurativa com "calça" e com "saia", buscando identificar e categorizar as práticas e dinâmicas de sentidos provenientes dessa relação. A relevância deste trabalho o destacou dentre os vários outros que integraram as apresentações realizadas no GT Corpo, Moda e Comunicação, que coordenamos no Colóquio de Moda no ano de 2014.

Pesquisadora atenta e curiosa aos fatos do cotidiano, Adriana se questionou sobre o motivo de as mulheres curitibanas não terem o hábito de usar saia. Como resposta inicial a esse questionamento (dada pelas próprias mulheres da capital paranaense em fóruns que a autora criou na internet), enfatizou-se o fato de que o uso da calça era revestido de dois valores: praticidade e segurança, sendo, pois, a peça considerada pelas usuárias como um "escudo" do corpo feminino com relação às "cantadas" masculinas, servindo de proteção contra certos assédios e constrangimentos. A partir disso, a autora buscou o entendimento histórico do uso da saia (e da calça) pelas muIheres, recuperando, inclusive, os sentidos simbólicos que essas vestimentas portam às usuárias e aos outros com os quais elas se relacionam socialmente.

A saia, produto de moda, ao mesmo tempo que atribui à mulher determinadas competências, aos olhos masculinos vulneráveis aos discursos da infinita submissão e objetivação do corpo feminino, deixa entrever partes da estrutura corpórea da mulher, inclusive ativando o imaginário dos homens com relação não apenas à sensualidade feminina, mas à sua sexualização. Elemento a partir do qual a mulher é sancionada cognitivamente de modo negativo, o uso da saia reforça no papel do feminino valores disfóricos de vulgaridade, de "disponibilidade", de libertinagem e de falta de respeito. Dessa perspectiva, "mulheres que se vestem com saia não se dão o valor e merecem ser, por isso, subjulgadas, inclusive passíveis de vários tipos de violência, da moral à física". Esse discurso reverbera uma conclusão falaciosa, pois julga determinados modos do feminino baseado em casos particulares e os generaliza para todos os tipos de casos de uso de saia, retirados de contextos bastante diferenciados e diversos.

Como poderá ser visto no trabalho de Adriana, a saia ou a calça é um objeto da indumentária sob o qual se constroem determinados modos de presença do feminino no mundo. Como objetos da moda, ambos desenham o corpo da mulher e a ele atribuem sentidos, inclusive na relação narratológica e dialógica que esse corpo estabelece com essas peças do vestuário. Tais presenças são textualizadas nos discursos publicitários das revistas analisadas, reiterando formas de o feminino ser e transitar pelo mundo - da liberdade e do despojamento à opressão e à constrição - ainda predominantemente masculino.

Ana Claudia de Oliveira e Marcelo Machado Martins 
artigo $]$

[ ADRIANA TULIO BAGGIO ]

Publicitária, mestre em Letras e doutora em Comunicação e Semiótica pela PUC-SP. Professora e pesquisadora no curso de Comunicação Social do Centro Universitário Uninter. Integrante do Centro de Pesquisas Sociossemióticas (CPS) da PUC-SP.

E-mail: atbaggio@gmail.com

\section{Saia ou calça?: construção publicitária de papéis sociais femininos}

Skirt or trousers?: advertising construction of female social roles

[resumo] Este trabalho trata dos direcionamentos teóricos e metodológicos de pesquisa sobre a construção do papel social feminino por meio da roupa na publicidade de revistas, considerando uma oposição entre o uso da saia e da calça. ${ }^{1}$ Apresenta pressupostos da semiótica discursiva e da sociossemiótica, mostrando a relevância de sua operação para uma semiótica da moda.

\section{palavras-chave}

saia; calça; semiótica da moda; sociossemiótica; publicidade.

[abstract] This paper deals with theoretical and methodological directions of a research on the construction of women's social role through clothing in magazines advertisements, considering an opposition between the use of the skirt and pants. It presents assumptions of discursive semiotics and sociosemiotics, showing the relevance of its operation for a semiotics of fashion.

[keywords] skirt; trousers; semiotics of fashion; sociosemiotics; advertising. 
Nosso objeto de estudo é a saia enquanto elemento significante na construção do papel social feminino em oposição à calça. 0 uso da calça se disseminou entre as mulheres ocidentais a partir dos anos 1970, tornando-se quase uma unanimidade, suplantando o uso da saia, que por muito tempo foi a única vestimenta - além do vestido - permitida às mulheres. Nosso corpusé constituido por anúncios publicitários veiculados em três revistas brasileiras de grande circulação: Veja, Exame e Claudia. Justificamos a escolha por esse tipo de discurso pelo fato de ser a publicidade (em seu sentido de espaço comercial em um veículo, comprado por um anunciante para divulgar sua marca, seus produtos, serviços ou ideias) um dos suportes privilegiados para o estudo das práticas e dinâmicas sociais de uma determinada época e cultura.

A saia enquanto objeto de estudo começou a se constituir para nós a partir de uma conversa sobre o fato de as mulheres curitibanas não terem o costume de usar tal peça de roupa. As especulações sobre o assunto deram origem a um texto, publicado na internet, que recebeu diversos comentários. Muitas moças confessaram evitar 0 uso da saia por receio de "cantadas" ou por questões de praticidade. Pesquisando mais sobre o assunto, nos deparamos com o trabalho da historiadora francesa Christine Bard, Ce que soulève la jupe (2010a). Bard conta que esse livro teria "se imposto" a ela enquanto escrevia outro, Histoire politique du pantalon (2010b), como se a saia representasse uma oposição natural à calça, da mesma forma que a mulher está em oposição ao homem, o feminino ao masculino. Oposição, aqui, no sentido de diferenciação e também como termos de uma axiologia, intrinsecamente relacionados por fazerem parte do mesmo paradigma.

No livro, Bard desnaturaliza e problematiza o uso da saia, mostrando seu papel não somente como figura de submissão à ordem masculina, mas também como símbolo de resistência aos ditames dessa mesma ordem. Se a saia ficou mais frequente em algumas manifestações ligadas aos direitos femininos, ela estaria sendo evitada pelas mulheres no dia a dia em razão do potencial risco de assédio ou de serem vistas como "disponíveis". Diferentemente da calça, a saia possui um aspecto de vulnerabilidade: as pernas ficam menos protegidas; dependendo do tecido de que é feita ou da modelagem, pode levantar com o vento; representa um limite corporal muito tênue em um ônibus ou metrô lotados; deixa o corpo da mulher mais exposto, já que "a abertura da vestimenta feminina evoca a facilidade de acesso ao sexo feminino, sua disponibilidade, sua penetrabilidade"2 (BARD, 2010b, p. 18).

Existem formas de assédio que acontecem justamente por essa vulnerabilidade do corpo vestido com saia. Em 2011, a imprensa curitibana noticiou que um "tarado" estaria filmando mulheres de saia e postando os vídeos na internet. Provavelmente havia uma microcâmera instalada no pé do voyeur, ou mesmo em uma cesta de supermercado, permitindo tomadas de baixo para cima. Um dos comentários sobre 0 assunto, postado em um fórum on-line, vê a atitude como um "castigo" merecido, relacionado ao jeito de se vestir: "[...] já faz tempo que as mulheres perderam a vergonha na cara e o respeito, elas acham que podem andar pelas ruas praticamente nuas e que é normal brincarem com o apetite sexual do homens"3.

A maior parte das situações apresentadas por Bard refere-se à França, mas não exclusivamente: a autora cita o caso da estudante brasileira Geisy Arruda, ameaçada por colegas da universidade por ter ido às aulas com um vestido muito curto. A partir daí, começamos a pesquisar outras situações em que o uso da saia estivesse condicionado por fatores que não a moda, ou o clima, ou o gosto pessoal. Encontramos diversos exemplos da saia relacionada ao assédio e à violência e, por outro lado, como roupa de protesto. Nas passeatas conhecidas como "Marcha das Vadias", por exemplo, muitas mulheres usam saias e carregam cartazes dizendo que o comprimento da saia não pode ser visto como motivo para estupro. Esses cartazes repudiam uma afirmação do senso comum, que culpa a mulher pela violência que ela sofre, entre outros motivos, pela roupa que veste.

E então nos perguntamos: se tais aspectos do uso da saia estão presentes nas práticas cotidianas, nos produtos culturais, nos discursos sobre gênero, de que forma estariam contribuindo para a construção dos papéis sociais femininos? E sendo a 
mídia, especialmente a publicidade, um dos suportes privilegiados para o estudo dos discursos contemporâneos, quais seriam os papéis sociais das mulheres presentes nos anúncios a partir do uso da saia ou da calça?

\section{Aspectos teóricos e metodológicos}

Vamos encontrar na semiótica postulada por Algirdas Julien Greimas e na sociossemiótica de Eric Landowski e Ana Claudia de Oliveira os principais aportes científicos e metodológicos que parecem dar conta, com muita propriedade, dos problemas que pretendemos investigar.

Nosso trabalho situa-se na articulação de dois campos da área de Comunicação: a moda e a publicidade. E é justamente na moda que se inscrevem os primeiros estudos de Greimas, nos quais já é possível perceber as bases da semiótica que desenvolveria nos anos seguintes. Em 1948, o semioticista lituano defenderia, na Sorbonne, sua tese de doutorado 4 intitulada La mode en 1830. Essai de description du vocabulaire vestimentaire d'après les journaux de modes de l'époque. Trata-se de um verdadeiro dicionário enciclopédico de mais de 3 mil vocábulos, que são analisados de acordo com sua origem, seu uso e sentido. Como explica Thomas F. Broden, em introdução ao volume onde a tese foi publicada:

[...] este texto acusa um interesse particular [de Greimas] pelo valor de indicador social das vestimentas e das expressões, buscando frequentemente precisar as conotações culturais relacionadas aos diferentes cortes e cores, denominações e epitetos. ${ }^{5}$ (citado por GREIMAS, 2000, p. XXVIII)

Para esse estudo, Greimas analisou, entre outros documentos, revistas femininas da época. Oliveira (2008) destaca que esse é um trabalho pré-semiótico, porque a unidade mínima de análise não é o texto como um todo, conforme um dos princípios básicos da disciplina, mas os vocábulos. Roland Barthes, inspirado pela tese de Greimas, desenvolverá, alguns anos mais tarde, seu Sistema da moda (2009, edição brasileira). Basicamente, para Greimas, os efeitos de sentido são dados pela articulação dos termos durante o uso (processo), ou seja, em sua manifestação, e não pela combinação a partir de um número limitado de regras (sistema), como vai postular Barthes. Uma diferença que irá se materializar em duas propostas teóricas distintas, como pontua Oliveira $(2008$, p. 2):

Oriundas de um mesmo arcabouço teórico, essas perspectivas opostas edificaram as novas bases de disciplinas que se desenvolveram ao longo da segunda metade do século XX. Enquanto Greimas edificou a semiótica como teoria da significação, Barthes, a semiologia, como ciência dos signos. Em ambas concretiza-se a disciplina maior projetada por Saussure, da qual a lingüística seria só uma parte.

Broden mostra ainda que, diferente de outras teorias sobre a moda como um sistema autônomo no qual as mudanças se dão internamente (incluindo a de Barthes), percebe-se que La mode en 1830 considera que as toilettes e os discursos verbais que as "vendem" nas revistas comunicam-se de maneira íntima com a história e a cultura (citado por GREIMAS, 2000, p. XIX-XXX), visão consolidada nos estudos atuais sobre moda.

Oliveira fala desse primeiro trabalho de Greimas em seu artigo sobre os discursos da aparência que se manifestam pela interação entre corpo e roupa, a partir do qual erige uma proposta de semiótica da moda. É sobre essa proposta que nos apoiamos para a metodologia de análise dos corpos vestidos no contexto dos anúncios.

Uma das primeiras questões a considerar é o objeto de estudo. Pretendemos semiotizar as práticas sociais em que a saia está envolvida e os discursos sobre ela (propondo, talvez, uma "semiótica da saia"). 0 objetivo desta etapa é verificar os sentidos 
que têm sido atribuídos a essa peça de roupa para verificar, na análise, se eles são reiterados ou não na construção do papel social da mulher por meio da publicidade.

A saia será tratada também em seu aspecto de modelagem, tecidos, cores, comprimentos, tipos. Na semiotização desses formantes, em relação com a história da moda e do vestuário, teremos outros subsídios para auxiliar na compreensão do uso da saia na publicidade.

Em cada uma dessas abordagens, a saia aparece em textos distintos. E em cada texto atuam os meios próprios de cada sistema. Dessa forma, o referente (a saia) não é externa aos textos. Como alerta Oliveira para essa importante formulação da semiótica, "[...] o referente é tecido na imanência de cada manifestação, que determina 0 vestido confeccionado no contexto interno da textualização e não no externo" (2008, p. 3). Os meios próprios da fotografia (ou da ilustração) e da publicidade vão tornar as roupas, nesses textos, distintas daquelas penduradas em um cabide, apresentadas num croqui ou vestidas no corpo de uma modelo na passarela.

As atuais operações semióticas desenvolvidas pelos estudiosos nos quais nos baseamos não abandonam os pressupostos da análise canônica do percurso gerativo de sentido. No entanto, a exemplo do trabalho de Oliveira (2008, p. 3), o que se busca nos diversos textos coletados é uma totalidade de sentido:

[...] o texto pode estar constituído previamente e ser assim tomado como unidade de estudo, mas também pode ser uma montagem de fragmentos relevantes de enunciados enunciados, ou de práticas sociais, que o analista recorta edificando uma totalidade de sentido.

É com base nesse procedimento que propomos a semiotização das práticas sociais com/sobre a saia e da saia enquanto peça de moda antes da análise semiótica, que será o coração da pesquisa. Continuamos a ter um referente que emerge dos textos, e não externo, como também explica Landowski (1992 p. 13-14, grifos do autor):

[...] o que se chama o referente não pode mais ser apreendido como um nível de realidade dado de antemão e puramente inerte. As totalidades que são usualmente designadas através desse termo serão consideradas, ao contrário, como realidades construídas, como resultados de operações de seleção ou de combinação que jogam com unidades semióticas mais elementares.

Em adição às totalidades tratadas na semiotização "geral" da saia, teremos, então, a totalidade formada pelo corpus de pesquisa. Como nosso objetivo é verificar a construção de papéis sociais femininos por meio da roupa nas publicidades de revistas, selecionamos três títulos desse tipo de publicação, veiculados no Brasil de agosto de 2011 a julho de 2012. Como já adiantamos, são a informativa semanal Veja, a de negócios e quinzenal Exame e a mensal e feminina Claudia.

\section{Semiótica da moda}

Uma das grandes contribuições da proposta de uma semiótica da moda de Oliveira é a metodologia para a análise do texto constituído pelo corpo vestido, dentro dos pressupostos mais gerais da disciplina. No que se refere às instâncias do enunciado e da enunciação, a semioticista diz:

[...] enunciado é o que a roupa no corpo produz no sujeito ou no objeto, tanto um enunciado de estado quanto um enunciado de transformação, que participa da sua definição cognitiva, pragmática, patêmica. A enunciação é como a roupa no corpo faz a visualidade gestual, postural, cinética daquele que, de uma dada maneira a portando significa para um outro. (OLIVEIRA, 2008, p. 5) 
Na instância do enunciado, a roupa no corpo produz o que o sujeito é ou a sua transformação para um outro estado. Oliveira explica que essa transformação não se dá somente pelo regime de junção, com base em um processo manipulatório, mas também pelo ajustamento do regime de união, quando a roupa torna-se sujeito em interação com o sujeito que a veste. No caso do nosso corpus, temos um enunciado em que a roupa não somente faz ser o sujeito, mas faz o sujeito fazer algo no contexto do anúncio publicitário - manipulatório por excelência. Um primeiro desafio que se apresenta é trabalhar com essa projeção de um enunciado em outro.

De início, pensamos que, por estarmos tratando de actantes, seria interessante notar a movimentação (ou ausência) das mulheres nos anúncios, indicando o percurso e a busca sugeridos pelas posturas. Esse é um dos critérios que observamos no início da análise. Nas publicidades, as mulheres aparecem sentadas e em pé, paradas ou flagradas num caminhar. Olham para outro sujeito no anúncio, ou para alhures, às vezes para nós, leitores, de forma franca e com um sorriso claro, ou de um jeito mais oblíquo, olhos semicerrados e meio sorriso. 0 que elas fazem enquanto sujeitos? Quais valores buscam? Por quem são destinadas? E nesses percursos, como age a roupa em interação com o corpo?

$\mathrm{Na}$ instância da enunciação, pelo processo de actorialização, espacialização e temporalização, perceberemos as marcas deixadas pelo enunciador em relação com o enunciatário, que constroem um modo de presença. Tais marcas se inscrevem em um discurso mais amplo, cultural e social. É nesse momento que podemos verificar a correspondência ou não com os modos de presença da saia nas práticas semiotizadas antes. A visualidade, a postura, a gestualidade e a cinética do corpo vestido, bem como os formantes plásticos dessas roupas, nos mostrarão os temas e valores que 0 enunciador partilha com o enunciatário. No caso dos anúncios, deveremos considerar que essa posição é composta não pelo sujeito que escolhe a roupa que vai vestir, mas pelo anunciante, a agência, os produtores da fotografia, os profissionais de criação envolvidos na elaboração da publicidade.

\section{Considerações finais: um exemplo de interação discursiva}

De cada uma dessas impressões transmitidas pelas roupas pode-se depreender uma ação, uma transformação no estado do sujeito, com o poder de gerar sentido e de mostrar um modo de presença da mulher - e também de sua relação com o homem, seu outro -, a exemplo do que fez a artista alemã Marianne Wex. Marianne tirou miIhares de fotos de homens e mulheres nas ruas de Hamburgo, no começo da década de 1970. ${ }^{6}$ Eles, de calça. Elas, na maioria, de saia ou vestido. Há uma diferença marcante em suas posturas, por causa do tipo de roupa e das constrições corporais provocadas por essas roupas. Enquanto as mulheres ocupam um mínimo de espaço, com os joelhos fechados e as pernas cruzadas, os homens abrem as pernas "[...] proporcionalmente ao seu grau de adesão à norma viril e tomam o máximo de espaço"7 (BARD, 2010a, p. 14).

É interessante observar nas fotografias de Wex que mesmo as poucas mulheres que vestem calça não estão de pernas abertas. Isso sugere que a prescrição da postura já foi assimilada e independe da roupa: meninas se sentam sempre de pernas fechadas. Talvez possamos dizer que essa gestualidade aprendida, a maneira de caminhar, os movimentos que são permitidos e os que são interditos são dados pela configuração de um papel temático do ser mulher, ou, pelo menos, de ser um determinado tipo de mulher.

As operações de articulação dos sistemas de corpo e roupa, e destes com a publicidade, em um único processo expressivo sincrético nos permite entender como o corpo feminino vestido com saia, e em oposição à calça, caracteriza o sujeito mulher, qualificando-a e qualificando a sociedade. 0 que a análise dos anúncios têm nos ajudado 
a descobrir é o mesmo que Oliveira (2008, p. 9) pergunta: "Que tipos de narratividade roupa e corpo estabelecem entre si? Que axiologias corpo e roupa veiculam e como essas são transferidas aos seus usuários?". E mais: que tipo de papel social feminino está presente nas publicidades quando as mulheres aparecem de saia ou de calça?

\section{NOTAS}

${ }^{[1]}$ Este trabalho apresenta os principais delineamentos da tese de doutorado defendida em março de 2015 no Programa de Estudos Pós-Graduados em Comunicação e Semiótica da PUC-SP. Trata dos objetivos, das hipóteses e dos principais conceitos teóricos e metodológicos que nortearam sua elaboração.

${ }^{[2]}$ No texto original: "[...] l'ouverture du vêtement féminin évoque la facilité de l'accès au sexe féminin, sa disponibilité, sa pénétrabilité". (Tradução nossa)

${ }^{[3]}$ Ver depoimento citado pelo usuário DeDz, postado às $13 \mathrm{~h} 15$ do dia 28/4/2011, no tópico "Cara tira foto das mulheres de saia em Curitiba", do site de fóruns HardMob. Disponivel em: <http://www.hardmob.com.br/ threads/443717-Cara-tira-foto-das-mulheres-de-saia-em-Curitiba>. Acesso em: 16 maio 2011.

${ }^{[4]}$ Greimas defendeu uma tese secundária no mesmo ano, Quelques reflets de la vie sociale en 1830 dans le vocabulaire des journaux de mode de l'époque (BRODEN citado por GREIMAS, 2000, p. XXIX).

${ }^{[5]}$ No original: "[...) ce texte accuse un intérêt particulier pour la valeur d'indice social des habillements et des expressions, cherchant souvent à préciser les connotations culturelles qui s'attachent aux différentes coupes et couleurs, dénominations et épithètes". (Tradução nossa)

${ }^{[6]}$ As fotografias foram publicadas no livro Let's take back our space: 'female' and 'male' body language as a result of patriarchal structures (1979). Uma página desse livro, que ilustra as diferentes configurações posturais de mulheres nos espaços públicos, pode ser vista em <http://www.flickr.com/photos/042/2677358657>. Acesso em: 6 jun. 2011.

${ }^{[7]}$ No original: "[...] proportionnellement à leur degré d'adhésion à la norme virile et prennent le maximum d'espace". (Tradução nossa)

\section{REFERÊNCIAS}

BARD, Christine. Ce que soulève la jupe. Paris: Autrement, 2010a.

Histoire politique du pantalon. Paris: Éditions du Seuil, $2010 b$.

BARTHES, Roland. Sistema da moda. São Paulo: Martins Fontes, 2009.

GREIMAS, Algirdas Julien. La mode en 1830: essai de description du vocabulaire vestimentaire d'après les journaux de modes de l'époque. Paris: PUF, 2000.

LANDOWSKI, Eric. Do referente, perdido e encontrado. Cruzeiro Semiótico, Lisboa, n. 17, jul. 1992, p. 9-15.

OLIVEIRA, Ana Claudia Mei Alves. de. Nas interações corpo e moda, os discursos da aparência. Caderno de Discussão do Centro de Pesquisas Sociossemióticas, São Paulo, v. 1, n. 14, nov. 2008. 